\title{
Application of Subsection Approximation Torque Curve Acceleration and Deceleration Motion Control Algorithm in Rigid Tapping of Drilling Center
}

\author{
$\mathrm{Xu} \mathrm{Liu}{ }^{1}$, Haixin $\mathrm{Zou}^{2}$, Xiangfa Kong ${ }^{3, *}$ and Jun $\mathrm{Lu}^{4}$ \\ ${ }^{1}$ Shenzhen Youqi Lighting Co. LTD. Shenzhen, 518035, China \\ ${ }^{2}$ Shenzhen Institute of Information Technology, Shenzhen 518172 \\ ${ }^{3}$ Engineering Training Center, School of Mechanical and Automotive Engineering, South China University of Technology, \\ Guangzhou 510641, China \\ ${ }^{4}$ Guangzhou Institutes of Biomedicine and Health (GIBH), Chinese Academy of Sciences, Guangzhou, 510530, China \\ ${ }^{*}$ Corresponding author
}

\begin{abstract}
Rigid tapping in drilling and tapping centers is an electromechanical control system with strong nonlinearity, uncertainty, and difficulty in accurate modeling. It will inevitably be affected by nonlinear and uncertain factors such as friction and mechanical resonance. The traditional motion control algorithm is difficult to fundamentally solve the contradiction between the rapid stability of the system response and the high stability accuracy. The electromagnetic torque is one of the most important physical quantities of the three-phase asynchronous motor, and the mechanical characteristics are the main characteristics of the motor; from these two aspects it is often inseparable to analyze the motor.
\end{abstract}

This paper proposed an algorithm of subsection approximating torque curve acceleration and deceleration and applied this algorithm to the rigid tapping engineering practice of CNC machine tools. The control method did not need to establish the exact mathematical model of the torque characteristics of the motor mechanical characteristics. The method of segment approximation achieves the modeling of the mechanical characteristic torque curve, has satisfied the comprehensive index requirements and technical feasibility of the system for rapidity and smoothness, and finally passed the test of the test platform and verified the actual tapping of the drilling.

Keywords—segmented approximation; mechanical characteristics; torque curve; servo spindle rigid tapping

\section{INTRODUCTION}

\section{A. Rigid Tapping Introduction}

The drilling and tapping center is a CNC machine tool for cutting metal. It is the most efficient and high-precision machine tool integrating cutting, drilling and tapping on the market. Compared with other $\mathrm{CNC}$ machine tools, the main features of the drilling and tapping center are compact and flexible, high displacement speed, high spindle speed, fast drilling and tapping, and fast tool change. The drilling and tapping center is favored by the market due to its high-speed, high-precision processing characteristics, and is a key equipment for the manufacture of product parts [1]. The tapping center tapping speed is one of the important indicators to measure the performance of machine tools.

As shown in Fig. 1, when the drilling and attack center is tapped rigidly, the spindle rotates one revolution, and the feed amount of the $Z$ axis should be equal to the pitch. If you control the rotation of the spindle and the feed of the $Z$ axis, the tapping accuracy can be guaranteed. Because the power and the corresponding gain of the spindle servo and the motion axis servo are not the same, the spindle rotation and the $\mathrm{Z}$ axis feed are not completely synchronized [2].
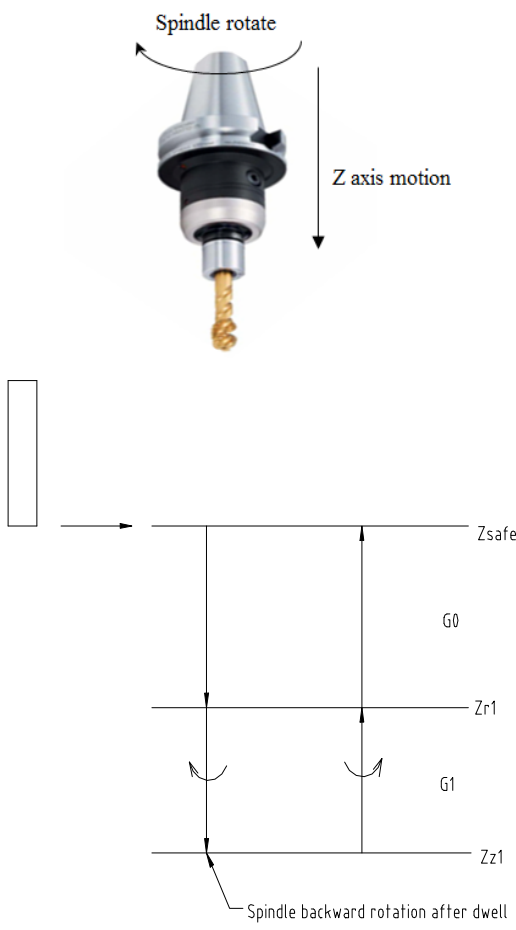

FIGURE I. SPINDLE RIGID TAPPING

The rigid tapping formula is as follows: 


$$
P=\frac{F}{S}
$$

P-taper pitch (mm) F-Z axis feed ( $\mathrm{mm} / \mathrm{min}) \mathrm{S}$-spindle speed (r/min)

\section{B. Following Error Compensation of Rigid Tapping}

Because the spindle servo drive and the Z-axis servo drive gain are not exactly matched during rigid tapping and are affected by nonlinear and uncertain factors such as friction force, mechanical resonance, etc., the spindle rotation and Zaxis feed are not completely synchronized. Since the servomotors of the motion axes (X-axis, Y-axis, and Z-axis) have faster response than the spindle servomotors, in order to ensure that the machine tool operates in an optimum state, generally the servomotors of the spindles are subjected to acceleration and deceleration motion control, and the motion axis servomotors are performed. Simultaneous movement, realtime monitoring of following error in the synchronization process, and appropriate adjustment of the incremental interpolation value of the movement axis can effectively improve the synchronization of the Z-axis and the spindle [3-4]. When performing low-speed rigid tapping, the spindle servo motor uses traditional acceleration/deceleration motion control algorithms, such as S-shaped algorithm, trigonometric function algorithm, and exponential algorithm, etc., which can basically meet the control requirements. However, when performing high-speed rigid tapping, traditional acceleration and deceleration motion control algorithms are difficult to fundamentally solve the contradiction between fast and stable system response and high stability accuracy and cannot meet the requirements of fast tapping and stability for rigid tapping of machining centers [7-12]. This paper proposed an approximation torque curve acceleration and deceleration motion control algorithm which can meet the requirements of high-speed rigid tapping control.

\section{Mechanical Characteristics of the Motor}

Under rated speed, the motor is basically constant torque speed, which means that the torque output by the motor would not be affected by the speed, it will only have a relationship with the load. Above the rated speed of the motor, the motor is constant power speed control mode, that is, the higher the speed, the smaller the torque [5]. Just as the car runs faster, the acceleration is slower. As shown in Fig. 2, the motor runs at rated speed (ie, constant torque speed control mode). Different acceleration and deceleration motion control algorithms have little effect, and when the motor runs beyond the rated speed (constant power speed control mode), the deceleration curve needs to be matched with the torque curve in order to ensure a small following error between the spindle motor and the motor of the movement axis, so as to meet the requirements of fast and stable system response and high stability and accuracy [6]. Due to different power spindle motor tapping speed, different pitch, different materials, the torque curve of the motor is different, so the error band of the following error is not the same. It is impractical to establish a general mathematical model of the motor's mechanical characteristic torque curve, therefore, this paper proposes a motion control algorithm for subsection-approximation torque curve acceleration and deceleration to achieve mathematical modeling of the mechanical characteristic torque curve of the spindle motor.

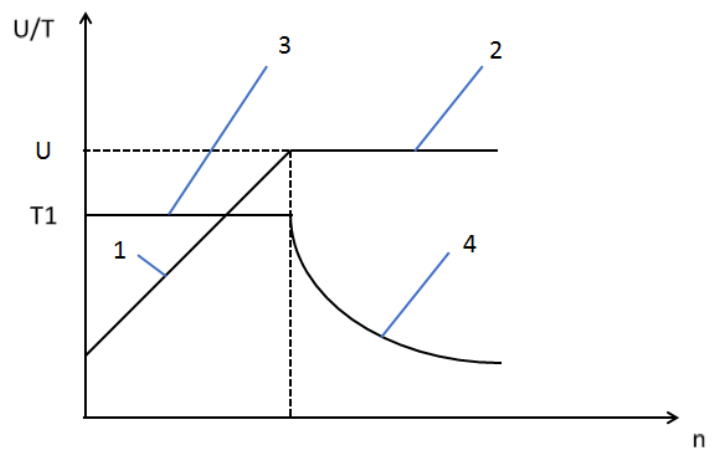

FIGURE II. MECHANICAL CHARACTERISTICS OF THE MOTOR

1: voltage curve at constant torque; 2 : voltage curve at constant power

3: Torque curve at constant torque; 4: Torque curve at constant power

\section{METHODS}

A. Subsection Approximation Torque Curve Acceleration and Deceleration Motion Control Algorithm

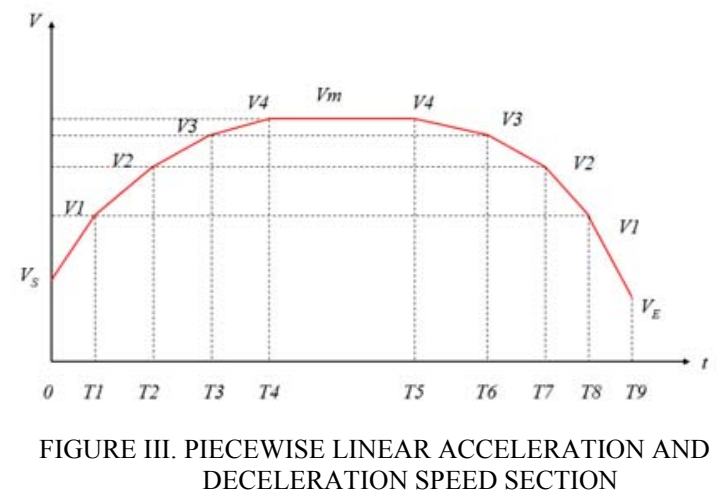

The segmental linear acceleration/deceleration speed segment diagram is shown in Fig. 3, and is divided into 9 segments. The acceleration segment is divided into 4 segments and the deceleration segment is divided into 4 segments. In the figure, V1, V2, V3, and V4 are the clamping speeds set by the system, which means that $\mathrm{V} 1$ is the maximum speed that the first straight line can reach, the starting speed is Vs, and the starting speed of the second speed is V1. The end speed is V2, that is, the maximum speed that the second straight line can reach is V2, and so on. In general, if V4 is set greater than Vm which is the maximum speed, then $\mathrm{Vm}$ is the precondition to calculation. If $\mathrm{V} 4$ is smaller than $\mathrm{Vm}$, then $\mathrm{Vm}=\mathrm{V} 4$ is taken.

According to Figure 3, the equations for the speed and displacement are as follows: 


$$
\mathrm{V}=\left\{\begin{array}{cc}
\mathrm{V}_{\mathrm{S}}+\mathrm{A} \mathrm{l}_{\mathrm{ac}} \times \mathrm{t} & \mathrm{t} \in\left[0, \mathrm{~T}_{1}\right) \\
\mathrm{V}_{1}+\mathrm{A} 2_{\mathrm{ac}} \times\left(\mathrm{t}-\mathrm{T}_{1}\right) & \mathrm{t} \in\left[\mathrm{T}_{1}, \mathrm{~T}_{2}\right) \\
\mathrm{V}_{2}+\mathrm{A} 3_{\mathrm{ac}} \times\left(\mathrm{t}-\mathrm{T}_{2}\right) & \mathrm{t} \in\left[\mathrm{T}_{2}, \mathrm{~T}_{3}\right) \\
\mathrm{V}_{3}+\mathrm{A} 4_{\mathrm{ac}} \times\left(\mathrm{t}-\mathrm{T}_{3}\right) & \mathrm{t} \in\left[\mathrm{T}_{3}, \mathrm{~T}_{4}\right) \\
\mathrm{V}_{\mathrm{m}} & \mathrm{t} \in\left[\mathrm{T}_{4}, \mathrm{~T}_{5}\right) \\
\mathrm{V}_{\mathrm{m}}-\mathrm{A} 4_{\mathrm{de}} \times\left(\mathrm{t}-\mathrm{T}_{5}\right) & \mathrm{t} \in\left[\mathrm{T}_{5}, \mathrm{~T}_{6}\right) \\
\mathrm{V}_{\mathrm{m}}-\mathrm{A} 3_{\mathrm{de}} \times\left(\mathrm{t}-\mathrm{T}_{6}\right) & \mathrm{t} \in\left[\mathrm{T}_{6}, \mathrm{~T}_{7}\right) \\
\mathrm{V}_{\mathrm{m}}-\mathrm{A} 2_{\mathrm{de}} \times\left(\mathrm{t}-\mathrm{T}_{7}\right) & \mathrm{t} \in\left[\mathrm{T}_{7}, \mathrm{~T}_{8}\right) \\
\mathrm{V}_{\mathrm{m}}-\mathrm{A} 1_{\mathrm{de}} \times\left(\mathrm{t}-\mathrm{T}_{8}\right) & \mathrm{t} \in\left[\mathrm{T}_{8}, \mathrm{~T}_{9}\right]
\end{array}\right.
$$

$$
S=\left\{\begin{array}{cc}
\mathrm{V}_{\mathrm{S}} \times \mathrm{t}+\frac{1}{2} \mathrm{~A} \mathrm{a}_{\mathrm{ac}} \times \mathrm{t}^{2} & \mathrm{t} \in\left[0, \mathrm{~T}_{1}\right) \\
\mathrm{V}_{1} \times\left(\mathrm{t}-\mathrm{T}_{1}\right)+\frac{1}{2} \mathrm{~A} 2_{\mathrm{ac}} \times\left(\mathrm{t}-\mathrm{T}_{1}\right)^{2} & \mathrm{t} \in\left[\mathrm{T}_{1}, \mathrm{~T}_{2}\right) \\
\mathrm{V}_{2} \times\left(\mathrm{t}-\mathrm{T}_{2}\right)+\frac{1}{2} \mathrm{~A} 3_{\mathrm{ac}} \times\left(\mathrm{t}-\mathrm{T}_{2}\right)^{2} & \mathrm{t} \in\left[\mathrm{T}_{2}, \mathrm{~T}_{3}\right) \\
\mathrm{V}_{3} \times\left(\mathrm{t}-\mathrm{T}_{3}\right)+\frac{1}{2} \mathrm{~A} 4_{\mathrm{ac}} \times\left(\mathrm{t}-\mathrm{T}_{3}\right)^{2} & \mathrm{t} \in\left[\mathrm{T}_{3}, \mathrm{~T}_{4}\right) \\
\mathrm{V}_{\mathrm{m}} \times\left(\mathrm{t}-\mathrm{T}_{4}\right) & \mathrm{t} \in\left[\mathrm{T}_{4}, \mathrm{~T}_{5}\right) \\
\mathrm{V}_{\mathrm{m}} \times\left(\mathrm{t}-\mathrm{T}_{5}\right)-\frac{1}{2} \mathrm{~A} 4_{\mathrm{de}} \times\left(\mathrm{t}-\mathrm{T}_{5}\right)^{2} & \mathrm{t} \in\left[\mathrm{T}_{5}, \mathrm{~T}_{6}\right) \\
\mathrm{V}_{\mathrm{m}} \times\left(\mathrm{t}-\mathrm{T}_{6}\right)-\frac{1}{2} \mathrm{~A} 3_{\mathrm{de}} \times\left(\mathrm{t}-\mathrm{T}_{6}\right)^{2} & \mathrm{t} \in\left[\mathrm{T}_{6}, \mathrm{~T}_{7}\right) \\
\mathrm{V}_{\mathrm{m}} \times\left(\mathrm{t}-\mathrm{T}_{7}\right)-\frac{1}{2} \mathrm{~A} 2_{\mathrm{de}} \times\left(\mathrm{t}-\mathrm{T}_{7}\right)^{2} & \mathrm{t} \in\left[\mathrm{T}_{7}, \mathrm{~T}_{8}\right) \\
\mathrm{V}_{\mathrm{m}} \times\left(\mathrm{t}-\mathrm{T}_{8}\right)-\frac{1}{2} \mathrm{~A} 1_{\mathrm{de}} \times\left(\mathrm{t}-\mathrm{T}_{8}\right)^{2} & \mathrm{t} \in\left[\mathrm{T}_{8}, \mathrm{~T}_{9}\right]
\end{array}\right.
$$

The acceleration $\mathrm{A}$ in the formula is solved as follows: A1ac, A2ac, A3ac, A4ac, A4de, A3de, A2de, and A1de in the speed formula are linear accelerations set by the system. There are two methods for setting the acceleration. One is the setting of direct constant acceleration and the other is the setting of the constant acceleration time. Here is a description of how to set the acceleration at a constant acceleration time (time constant).

Set T1ac, T2ac, T3ac, T4ac, T4de, T3de, T2de and T1de as the acceleration and deceleration time constants set by the system, and then use the set linear speeds and time constants to determine the acceleration of each linear segment:

$$
\left\{\begin{array}{l}
\mathrm{A} 1_{\mathrm{ac}}=\frac{\left(\mathrm{V}_{1}-\mathrm{V}_{\mathrm{S}}\right)}{\mathrm{T} \mathrm{ac}_{\mathrm{ac}}} \\
\mathrm{A} 2_{\mathrm{ac}}=\frac{\left(\mathrm{V}_{2}-\mathrm{V}_{1}\right)}{\mathrm{T} 2_{\mathrm{ac}}} \\
\mathrm{A} 3_{\mathrm{ac}}=\frac{\left(\mathrm{V}_{3}-\mathrm{V}_{2}\right)}{\mathrm{T} 3_{\mathrm{ac}}} \\
\mathrm{A} 4_{\mathrm{ac}}=\frac{\left(\mathrm{V}_{4}-\mathrm{V}_{3}\right)}{\mathrm{T} 4_{\mathrm{ac}}} \\
\mathrm{A} 4_{\mathrm{de}}=\frac{\left(\mathrm{V}_{4}-\mathrm{V}_{3}\right)}{\mathrm{T} 4_{\mathrm{de}}} \\
\mathrm{A} 3_{\mathrm{de}}=\frac{\left(\mathrm{V}_{3}-\mathrm{V}_{2}\right)}{\mathrm{T} 3_{\mathrm{de}}} \\
\mathrm{A} 2_{\mathrm{de}}=\frac{\left(\mathrm{V}_{2}-\mathrm{V}_{1}\right)}{\mathrm{T} 2_{\mathrm{de}}} \\
\mathrm{A} 1_{\mathrm{de}}=\frac{\left(\mathrm{V}_{\mathrm{E}}-\mathrm{V}_{1}\right)}{\mathrm{T} 1_{\mathrm{de}}}
\end{array}\right.
$$

Dissolve the displacement $\mathrm{Si}$ and the segmentation time $\mathrm{Ti}$ in each segment of the formula. Substituting equation (4) into equation (3) yields:

$$
\left\{\begin{array}{l}
\mathrm{S}_{1}=\frac{\mathrm{V}_{1}^{2}-\mathrm{V}_{\mathrm{S}}^{2}}{2 \times \mathrm{Al} 1_{\mathrm{ac}}} \\
\mathrm{S}_{2}=\frac{\mathrm{V}_{2}^{2}-\mathrm{V}_{1}^{2}}{2 \times \mathrm{A} 2_{\mathrm{ac}}} \\
\mathrm{S}_{3}=\frac{\mathrm{V}_{3}^{2}-\mathrm{V}_{2}^{2}}{2 \times \mathrm{A} 3_{\mathrm{ac}}} \\
\mathrm{S}_{4}=\frac{\mathrm{V}_{4}^{2}-\mathrm{V}_{3}^{2}}{2 \times \mathrm{A} 4_{\mathrm{ac}}} \\
\mathrm{S}_{5}=\mathrm{V}_{\mathrm{m}} \times \mathrm{T}_{5} \\
\mathrm{~S}_{6}=\frac{\mathrm{V}_{4}^{2}-\mathrm{V}_{3}^{2}}{2 \times \mathrm{A} 4_{\mathrm{de}}} \\
\mathrm{S}_{7}=\frac{\mathrm{V}_{3}^{2}-\mathrm{V}_{2}^{2}}{2 \times \mathrm{A} 3_{\mathrm{de}}} \\
\mathrm{S}_{8}=\frac{\mathrm{V}_{2}^{2}-\mathrm{V}_{1}^{2}}{2 \times \mathrm{A} 2_{\mathrm{de}}} \\
\mathrm{S}_{9}=\frac{\mathrm{V}_{1}^{2}-\mathrm{V}_{\mathrm{E}}^{2}}{2 \times \mathrm{A} 1_{\mathrm{de}}}
\end{array}\right.
$$

Substituting equation (4) into equation (2) yields:

$$
\left\{\begin{array}{l}
\mathrm{T}_{1}=\frac{\left(\mathrm{V}_{1}-\mathrm{V}_{\mathrm{S}}\right)}{\mathrm{V}_{1}} \times \mathrm{Tl}_{\mathrm{ac}} \\
\mathrm{T}_{2}=\frac{\left(\mathrm{V}_{2}-\mathrm{V}_{1}\right)}{\mathrm{V}_{1}} \times \mathrm{T}_{\mathrm{ac}} \\
\mathrm{T}_{3}=\frac{\left(\mathrm{V}_{3}-\mathrm{V}_{2}\right)}{\mathrm{V}_{2}} \times \mathrm{T}_{\mathrm{ac}} \\
\mathrm{T}_{4}=\frac{\left(\mathrm{V}_{4}-\mathrm{V}_{3}\right)}{\mathrm{V}_{3}} \times \mathrm{T}_{\mathrm{ac}} \\
\mathrm{T}_{5}=\frac{\mathrm{S}_{5}}{\mathrm{~V}_{\mathrm{m}}} \\
\mathrm{T}_{6}=\frac{\left(\mathrm{V}_{4}-\mathrm{V}_{3}\right)}{\mathrm{V}_{3}} \times \mathrm{T}_{\mathrm{de}} \\
\mathrm{T}_{7}=\frac{\left(\mathrm{V}_{3}-\mathrm{V}_{2}\right)}{\mathrm{V}_{2}} \times \mathrm{T}_{\mathrm{ac}} \\
\mathrm{T}_{8}=\frac{\left(\mathrm{V}_{2}-\mathrm{V}_{1}\right)}{\mathrm{V}_{1}} \times \mathrm{T}_{2} \mathrm{de} \\
\mathrm{T}_{9}=\frac{\left(\mathrm{V}_{1}-\mathrm{V}_{\mathrm{E}}\right)}{\mathrm{V}_{1}} \times \mathrm{Tl}_{\mathrm{de}}
\end{array}\right.
$$

\section{B. Special Case Processing of the Subsection Approach Torque Curve Acceleration And Deceleration Motion Control Algorithm}

The speed, displacement and time of the complete curve of the subsection approach torque curve acceleration/deceleration motion control algorithm are explained in detail above, but when the curve is not a complete four-stage linear acceleration/deceleration (such as medium speed or low speed rigid tapping), you need to back-calculate according to the actual tapping depth and setting speed. The following example illustrates the derivation of the speed, displacement and time of each segment curve when the actual maximum tapping speed can only reach between $\mathrm{V} 2$ and $\mathrm{V} 3$. 


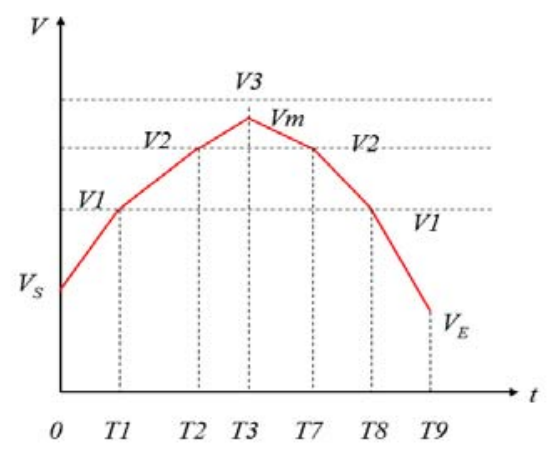

FIGURE IV. PARTICULAR LINEAR ACCELERATION AND DECELERATION SPECIAL CASE

As shown in Fig. 4, the speed of the piecewise linear acceleration/deceleration is divided into 6 sections, the acceleration and deceleration sections are divided into 3 sections respectively. The maximum spindle speed can reach $\mathrm{Vm}$ (V3 is greater than $\mathrm{Vm}$ ). According to Figure 4, the equations for the speed and displacement can be drawn as follows:

$$
\mathrm{V}=\left\{\begin{array}{cc}
\mathrm{V}_{\mathrm{S}}+\mathrm{A} 1_{\mathrm{ac}} \times \mathrm{t} & \mathrm{t} \in\left[0, \mathrm{~T}_{1}\right) \\
\mathrm{V}_{1}+\mathrm{A} 2_{\mathrm{ac}} \times\left(\mathrm{t}-\mathrm{T}_{1}\right) & \mathrm{t} \in\left[\mathrm{T}_{1}, \mathrm{~T}_{2}\right) \\
\mathrm{V}_{2}+\mathrm{A} 3_{\mathrm{ac}} \times\left(\mathrm{t}-\mathrm{T}_{2}\right) & \mathrm{t} \in\left[\mathrm{T}_{2}, \mathrm{~T}_{3}\right) \\
\mathrm{NE} & \mathrm{t} \in\left[\mathrm{T}_{3}, \mathrm{~T}_{4}\right) \\
\mathrm{NE} & \mathrm{t} \in\left[\mathrm{T}_{4}, \mathrm{~T}_{5}\right) \\
\mathrm{NE} & \mathrm{t} \in\left[\mathrm{T}_{5}, \mathrm{~T}_{6}\right) \\
\mathrm{V}_{\mathrm{m}}-\mathrm{A} 3_{\mathrm{de}} \times\left(\mathrm{t}-\mathrm{T}_{6}\right) & \mathrm{t} \in\left[\mathrm{T}_{6}, \mathrm{~T}_{7}\right) \\
\mathrm{V}_{\mathrm{m}}-\mathrm{A} 2_{\mathrm{de}} \times\left(\mathrm{t}-\mathrm{T}_{7}\right) & \mathrm{t} \in\left[\mathrm{T}_{7}, \mathrm{~T}_{8}\right) \\
\mathrm{V}_{\mathrm{m}}-\mathrm{A} 1_{\mathrm{de}} \times\left(\mathrm{t}-\mathrm{T}_{8}\right) & \mathrm{t} \in\left[\mathrm{T}_{8}, \mathrm{~T}_{9}\right]
\end{array}\right.
$$

$$
\mathrm{S}=\left\{\begin{array}{cc}
\mathrm{V}_{\mathrm{S}} \times \mathrm{t}+\frac{1}{2} \mathrm{~A} \mathrm{l}_{\mathrm{ac}} \times \mathrm{t}^{2} & \mathrm{t} \in\left[0, \mathrm{~T}_{1}\right) \\
\mathrm{V}_{1} \times\left(\mathrm{t}-\mathrm{T}_{1}\right)+\frac{1}{2} \mathrm{~A} 2_{\mathrm{ac}} \times\left(\mathrm{t}-\mathrm{T}_{1}\right)^{2} & \mathrm{t} \in\left[\mathrm{T}_{1}, \mathrm{~T}_{2}\right) \\
\mathrm{V}_{2} \times\left(\mathrm{t}-\mathrm{T}_{2}\right)+\frac{1}{2} \mathrm{~A} 3_{\mathrm{ac}} \times\left(\mathrm{t}-\mathrm{T}_{2}\right)^{2} & \mathrm{t} \in\left[\mathrm{T}_{2}, \mathrm{~T}_{3}\right) \\
\mathrm{NE} & \mathrm{t} \in\left[\mathrm{T}_{3}, \mathrm{~T}_{4}\right) \\
\mathrm{NE} & \mathrm{t} \in\left[\mathrm{T}_{4}, \mathrm{~T}_{5}\right) \\
\mathrm{NE} & \mathrm{t} \in\left[\mathrm{T}_{5}, \mathrm{~T}_{6}\right) \\
\mathrm{V}_{\mathrm{m}} \times\left(\mathrm{t}-\mathrm{T}_{6}\right)-\frac{1}{2} \mathrm{~A} 3_{\mathrm{de}} \times\left(\mathrm{t}-\mathrm{T}_{6}\right)^{2} & \mathrm{t} \in\left[\mathrm{T}_{6}, \mathrm{~T}_{7}\right) \\
\mathrm{V}_{\mathrm{m}} \times\left(\mathrm{t}-\mathrm{T}_{7}\right)-\frac{1}{2} \mathrm{~A} 2_{\mathrm{de}} \times\left(\mathrm{t}-\mathrm{T}_{7}\right)^{2} & \mathrm{t} \in\left[\mathrm{T}_{7}, \mathrm{~T}_{8}\right) \\
\mathrm{V}_{\mathrm{m}} \times\left(\mathrm{t}-\mathrm{T}_{8}\right)-\frac{1}{2} \mathrm{~A} 1_{\mathrm{de}} \times\left(\mathrm{t}-\mathrm{T}_{8}\right)^{2} & \mathrm{t} \in\left[\mathrm{T}_{8}, \mathrm{~T}_{9}\right]
\end{array}\right.
$$

The acceleration A in the formula is solved as follows: in the formula, NE means that there is no acceleration, and the acceleration is set by the constant acceleration time (time constant). Each acceleration of linear segment can be obtained by using the clamping speed and time constant for each linear segment:

$$
\left\{\begin{array}{l}
\mathrm{A} 1_{\mathrm{ac}}=\frac{\left(\mathrm{V}_{1}-\mathrm{V}_{\mathrm{S}}\right)}{\mathrm{T} 1_{\mathrm{ac}}} \\
\mathrm{A} 2_{\mathrm{ac}}=\frac{\left(\mathrm{V}_{2}-\mathrm{V}_{1}\right)}{\mathrm{T} 2_{\mathrm{ac}}} \\
\mathrm{A} 3_{\mathrm{ac}}=\frac{\left(\mathrm{V}_{3}-\mathrm{V}_{2}\right)}{\mathrm{T} 3_{\mathrm{ac}}} \\
\mathrm{A} 3_{\mathrm{de}}=\frac{\left(\mathrm{V}_{3}-\mathrm{V}_{2}\right)}{\mathrm{T} 3_{\mathrm{de}}} \\
\mathrm{A} 2_{\mathrm{de}}=\frac{\left(\mathrm{V}_{2}-\mathrm{V}_{1}\right)}{\mathrm{T} 2_{\mathrm{de}}} \\
\mathrm{A} 1_{\mathrm{de}}=\frac{\left(\mathrm{V}_{\mathrm{E}}-\mathrm{V}_{1}\right)}{\mathrm{T} 1_{\mathrm{de}}}
\end{array}\right.
$$

Dissolve the displacement $\mathrm{Si}$ and the segmentation time Ti in each segment of the formula. Substituting equation (9) into equation (8) yields:

$$
\left\{\begin{array}{l}
\mathrm{S}_{1}=\frac{\mathrm{V}_{1}^{2}-\mathrm{V}_{\mathrm{S}}^{2}}{2 \times \mathrm{A} 1_{\mathrm{ac}}} \\
\mathrm{S}_{2}=\frac{\mathrm{V}_{2}^{2}-\mathrm{V}_{1}^{2}}{2 \times \mathrm{A} 2_{\mathrm{ac}}} \\
\mathrm{S}_{3}=\frac{\mathrm{V}_{\mathrm{m}}^{2}-\mathrm{V}_{2}^{2}}{2 \times \mathrm{A} 3_{\mathrm{ac}}} \\
\mathrm{S}_{7}=\frac{\mathrm{V}_{\mathrm{m}}^{2}-\mathrm{V}_{2}^{2}}{2 \times \mathrm{A} 3_{\mathrm{de}}} \\
\mathrm{S}_{8}=\frac{\mathrm{V}_{2}^{2}-\mathrm{V}_{1}^{2}}{2 \times \mathrm{A} 2_{\mathrm{de}}} \\
\mathrm{S}_{9}=\frac{\mathrm{V}_{1}^{2}-\mathrm{V}_{\mathrm{E}}^{2}}{2 \times \mathrm{A} 1_{\mathrm{de}}}
\end{array}\right.
$$

Combining equation $S_{\text {Total }}=S 1+S 2+S 3+S 7+S 8+S 9$, there is:

$$
V_{m}=\sqrt{V_{2}^{2}+2 \times \frac{A 3_{a c}+A 3_{d e}}{A 3_{a c} \times A 3_{d e}} \times\left(S_{\text {Total }}-S 1-S 2-S 8-S 9\right)}
$$

Substituting equation (11) into equation (7) yields: 


$$
\left\{\begin{array}{l}
\mathrm{T}_{1}=\frac{\left(\mathrm{V}_{1}-\mathrm{V}_{\mathrm{S}}\right)}{\mathrm{V}_{1}} \times \mathrm{Tl}_{\mathrm{ac}} \\
\mathrm{T}_{2}=\frac{\left(\mathrm{V}_{2}-\mathrm{V}_{1}\right)}{\mathrm{V}_{1}} \times \mathrm{T}_{\mathrm{ac}} \\
\mathrm{T}_{3}=\frac{\left(\mathrm{V}_{\mathrm{m}}-\mathrm{V}_{2}\right)}{\mathrm{V}_{2}} \times \mathrm{T}_{\mathrm{ac}} \\
\mathrm{T}_{7}=\frac{\left(\mathrm{V}_{\mathrm{m}}-\mathrm{V}_{2}\right)}{\mathrm{V}_{2}} \times \mathrm{T}_{\mathrm{ac}} \\
\mathrm{T}_{8}=\frac{\left(\mathrm{V}_{2}-\mathrm{V}_{1}\right)}{\mathrm{V}_{1}} \times \mathrm{T}_{\mathrm{de}} \\
\mathrm{T}_{9}=\frac{\left(\mathrm{V}_{1}-\mathrm{V}_{\mathrm{E}}\right)}{\mathrm{V}_{1}} \times \mathrm{T} 1_{\mathrm{de}}
\end{array}\right.
$$

The actual completion of the maximum tapping speed is between V2 and V3, and the derivation of the speed, displacement, and time parameters of each segment of the curve shown above performed the special cases of incomplete linear acceleration and deceleration of the motion parameters. The other special cases could be solved by the same way.

\section{Rigid Tapping Experiment}

Using the self-developed CNC system, the system can be set to open/close the acceleration/deceleration motion control algorithm of the subsection approach torque curve by using the system parameter settings. When closed, the conventional Sshaped acceleration/deceleration control algorithm is used to tap; when opened, the subsection approach torque curve acceleration and deceleration motion control algorithm is used.

The purpose of the experiment is to compare tapping experiments using conventional S-shaped acceleration/deceleration control algorithms with tapping and subsection approaching torque curve acceleration/deceleration motion control algorithms, to verify that the new algorithm is superior to conventional acceleration/deceleration algorithm control.

To use segmented acceleration and deceleration motion control algorithms could make the motor torque approach the torque curve when running, so as to meet the system's comprehensive index requirements for rapidity and stability, as well as technical feasibility.

Experimental equipment: drilling and attack center with independent research and development of CNC system.

Tapping experiment $\mathrm{G}$ code:

$\%$

\section{G54G17G80G90G40G49G0}

M03S3000 //set spindle speed according to experimental conditions.

\section{G0X0Y0Z10}

G91G81X0Y0Z-25R5F3000 //set z-axis feed speed according to experimental conditions.

$\mathrm{X} 7 \mathrm{~K} 20$

G80

M30

$\%$
Note: By modifying $\mathrm{S}$ and $\mathrm{F}$, rigid tapping with different rotational speeds and pitches is performed.

Experimental data acquisition:

The software internally monitors the feedback value of the spindle and Z-axis motor encoder in real time. The difference is the error value e $(\mathrm{k})$. A real-time sampled error value is generated for "trajectory tracking" files and error maps for data analysis. The internal software of the system is designed as follows:

$$
\begin{aligned}
& \text { Uint16 G1_rigid_Error (Uint16 e) } \\
& \left\{\begin{array}{l}
* * * * * * \\
\text { (U) }
\end{array}\right.
\end{aligned}
$$

// absolute encoder feedback value of spindle motor

$\mathrm{S}_{-}$Encoder. Position Value $=$get_ $\mathrm{MACH}_{-}$value $\left(\& \mathrm{~S}_{-}\right.$ Encoder);

//absolute encoder feedback value of $\mathrm{Z}$ axis motor

Z_Encoder. Position Value = get_MACH_value (\&Z_Encoder);

//Error e (k)

error $\quad=\quad$ S_Encoder.PositionValue

Z Encoder.PositionValue;

$* * * * * *$

Return error;

The comparison of the old and new algorithms following the error band data is shown in Figure 5:

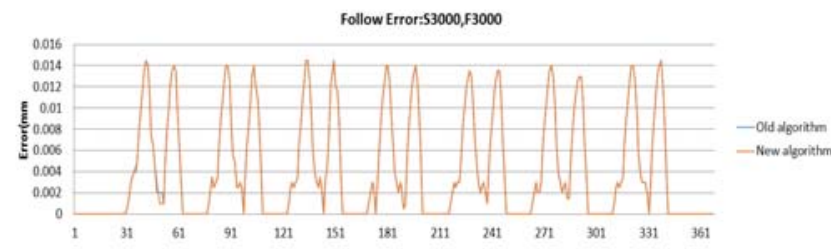

FIGURE V. A S3000, F3000 FOLLOWING THE ERROR BAND

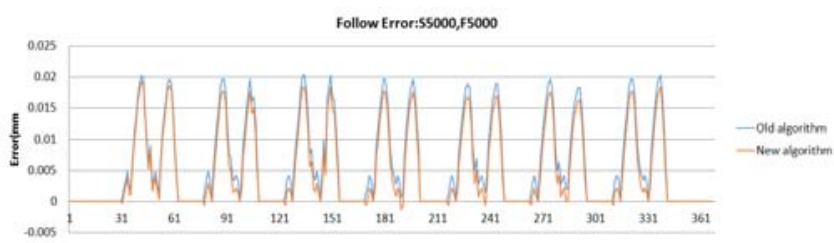

FIGURE V. B S5000. F5000 FOLLOWING THE ERROR BAND 


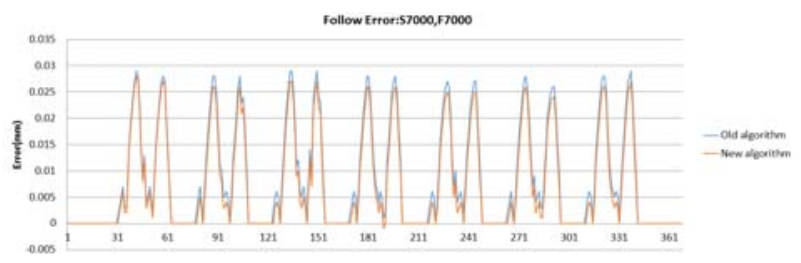

FIGURE V. C S7000, F7000 FOLLOWING THE ERROR BAND

\section{Experimental Result}

By modifying the settings of $\mathrm{S}$ and $\mathrm{F}$ (combining different rotation speeds and different pitches), a large number of rigid tapping experiments were performed. Experimental results show:

During low-speed tapping, the following error of the conventional acceleration/deceleration motion control algorithm and the new algorithm is distributed in the same interval, and the tapping effect can meet the accuracy requirements;

In the middle-speed tapping, the conventional algorithm in the high-speed segment due to acceleration and deceleration curve acceleration is too large, the spindle motor servo drive response is not fast enough, resulting in increased following error between the spindle servo motor and the feed axis motor, the middle of the thread teeth type has a little bit of cut, smooth finish is not enough;

During high-speed tapping, the follow-up error between the axis servo motor and the feed axis motor of the conventional algorithm is significantly increased, the entire tapping surface has severe over-cut teeth, and the tapping fails; the new algorithm can effectively solve this problem, and satisfies the requirements of the comprehensive index for the rapidity and smoothness of the system.

\section{CONCLUSIONS}

Traditional acceleration and deceleration motion control algorithms are difficult to fundamentally solve the contradiction between fast and stable system response and high stability accuracy and cannot meet the requirements of fast tapping and stability for rigid tapping of machining centers. This paper proposed an algorithm of subsection approximating torque curve acceleration and deceleration and applied this algorithm to the rigid tapping engineering practice of $\mathrm{CNC}$ machine tools. The method of segment approximation achieves the modeling of the mechanical characteristic torque curve, has satisfied the comprehensive index requirements and technical feasibility of the system for rapidity and smoothness, and finally passed the test of the test platform and verified the actual tapping of the drilling.

\section{ACKNOWLEDGMENT}

This work is supported by (1)Guangzhou NLKER Precision Machine Tool co., Ltd; (2)Guangzhou Xinyue CNC Co.,Ltd; (3) Guangzhou Yuchuang electronic technology co. LTD.; (4) Guangzhou Puyue precision equipment co. LTD.; (5) Shenzhen Youqi Lighting co. LTD. The authors gratefully acknowledge the critical review of anonymous referees. The authors would also like to thank all the anonymous reviewers for many useful comments on this paper.

\section{REFERENCES}

[1] LIU Jiang, LAI Lixun: Research and optimization of the high speed cutting technology of the drilling center [J], Manufacturing Technology and Machine Tool,2014-12-02.

[2] Lu Jun;Zou Hai xin;Shen Lie;Zou Xiang jun, Applicationof Adaptive Fuzzy-PID Control in Servo Spindle Rigid Tapping[J], Advanced Measurement and Test, 2011-06-24

[3] $\Sigma$ V serial servo pack user manual, Published in China 2008-10.

[4] FENG Guanglei,CUI Gangwei,HU Chuanyong,etc..,Research on high speed rigid tapping optimization technology of $\mathrm{CNC}$ machine tool[J], Manufacturing Technology and Machine Tool, 2017-07-02

[5] Electrical engineering (fourth edition), Tsinghua University press.2008.

[6] Motor drive and control, Tianjin University press, 2008

[7] Luo Hui, Research of motion control method on open CNC system[M], Shanghai university of engineering and technology.,2016-06-01

[8] Chen Bin, The research and implementation about the nonlinear motion control interpolation algorithm for the CNC system[M], Guangzhou university, 2016-05-01

[9] Xu DongWei, Research and Develpment of Motion Control Algorithm for Multi-axis CNC system ,Guangdong university of technology,201506-01

[10] Lu Aiming, Study on the Control System of the High-Speed and Highprecision Positioning Table for Higeh-End Manufacturing Equipment [M], Hefei university of technology, 2013-04-01

[11] Xiao Leping, Study and Design of Acceleration/Deceleration Algorithm for CNC [M] South China university of technology 2012-06-01

[12] Hu Zehua, Research on key technologies of High-performance five-axis $\mathrm{CNC}[\mathrm{M}]$, Guangdong university of technology,2012-06-01. 